\title{
UREIA DE LIBERAÇÃO LENTA APLICADA SUPERFICIALMENTE E UREIA COMUM INCORPORADA AO SOLO NO RENDIMENTO DO MILHO ${ }^{1}$
}

\author{
Ederson Antonio Civardi², Américo Nunes da Silveira Neto², \\ Vilmar Antonio Ragagnin ${ }^{2}$, Eloene Rodriges Godoy², Elias Brod ${ }^{2}$
}

\section{ABSTRACT \\ SLOW-RELEASE UREA APPLIED \\ TO SURFACE AND REGULAR UREA INCORPORATED TO SOIL ON MAIZE YIELD}

Urea applied to the soil surface results in high losses of nitrogen $(\mathrm{N})$ by volatilization of $\mathrm{NH}_{3}$. The use of polymers covering urea granules is an alternative management to reduce such losses. The experiment was carried out in Entisols (Quartzipsament), with 6\% of clay, in the 2007/2008 harvest, in Jataí, Goiás State, Brazil, in order to assess the efficiency of the following management systems: urea incorporated to the soil and polymer coated urea applied to the surface, concerning the agronomic and economic aspects of maize cultivation. It was implemented an experimental design in randomized blocks, with eight replications, totaling 24 plots. The covering nitrogen fertilization was performed in a single application, at the $\mathrm{V}_{5}$ stage. The urea incorporated to the soil resulted in higher values related to ear length and diameter, number of grains per ear, mass of one hundred grains, and relation between earned revenue and invested capital. The highest grain yield and profitability were obtained with the application of urea incorporated to the soil. For each Real (R\$1.00) invested in the cultivation, the urea incorporated to the soil produced $\mathrm{R} \$ 1.37$ as profit.

KEY-WORDS: Zea mays L.; slow-release fertilizer; nitrogen; polymers; no-tillage system.

\section{INTRODUÇÃO}

O nitrogênio é um dos nutrientes mais limitantes no solo e um dos mais requeridos pelas plantas cultivadas, para elevar a produção e o índice de colheita. O milho é um exemplo de cultura onde o nitrogênio é empregado em grandes quantidades, na forma de fertilizantes minerais. A principal fonte de nitrogênio utilizada no Brasil é a ureia, que apresenta como vantagens a alta concentração de $\mathrm{N}$ e o menor preço de $\mathrm{N}$ por unidade. Possui, ainda, alta

\section{RESUMO}

A ureia aplicada sobre a superfície do solo apresenta elevadas perdas de nitrogênio $(\mathrm{N})$, por volatilização de $\mathrm{NH}_{3}$. O uso de polímeros recobrindo grânulos de ureia é uma alternativa de manejo para reduzir tais perdas. O trabalho, desenvolvido em Neossolo Quartzarênico, com 6\% de argila, na safra 2007/2008, no município de Jataí (GO), teve por objetivo avaliar a eficiência dos seguintes manejos: ureia incorporada ao solo e ureia revestida com polímeros, aplicada em superfície, nos aspectos agronômicos e econômicos da cultura do milho. Adotou-se o delineamento experimental em blocos casualizados, com oito repetições, totalizando 24 parcelas. A adubação nitrogenada de cobertura foi realizada em uma única aplicação, no estádio $V_{5}$. A ureia incorporada ao solo proporcionou maiores valores de comprimento da espiga, diâmetro da espiga, número de grãos por espiga, massa de cem grãos, produtividade de grãos e da relação entre a receita obtida e o valor investido. O maior rendimento de grãos e a maior lucratividade foram obtidos com a aplicação da ureia incorporada ao solo. Para cada real $(\mathrm{R} \$ 1,00)$ investido na cultura, a ureia incorporada ao solo promoveu retorno de $\mathrm{R} \$ 1,37$.

PALAVRAS-CHAVE: Zea mays L.; fertilizante de liberação lenta; nitrogênio; polímeros; sistema plantio direto.

solubilidade, menor corrosividade e compatibilidade com muitos fertilizantes. Contudo, apresenta desvantagens, como a possibilidade de perdas de $\mathrm{N}$ por volatilização de $\mathrm{NH}_{3}$, fitoxidez de biureto e perdas por lixiviação (Cantarella 2007).

No Brasil, o consumo anual total de N, em 2006, foi de 2,3 milhões de toneladas, sendo que a ureia é o fertilizante mais usado, representando $53,14 \%$ do total consumido. O País produz 811,1 mil toneladas $(35,26 \%)$ e importa $1.490,7$ mil toneladas de nitrogênio (64,75\%) (IFA 2009).

1. Trabalho recebido em nov./2009 e aceito para publicação em jan./2011 (nº registro: PAT 8146/ DOI 10.5216/pat.v41i1.8146).

2. Universidade Federal de Goiás, Campus Jataí, Faculdade de Agronomia, Jataí, GO, Brasil. E-mails: eaccivardi@yahoo.com.br, americonunesagro@yahoo.com.br, vilmar.ragagnin@gmail.com, eloene_5@hotmail.com, elias.agronomia@gmail.com. 
A perda do nitrogênio pode ocorrer quando o solo apresenta $\mathrm{pH}$ alcalino, baixa capacidade de troca de cátions, baixa capacidade tampão do hidrogênio, alta temperatura, baixa umidade e altas doses de nitrogênio, ou pela ação conjunta de dois ou mais destes fatores (Oliveira \& Balbino 1995). Isto, em parte, ocorre por meio dos processos de lixiviação do nitrato, volatilização da amônia, desnitrificação e erosão do solo.

A volatilização é a perda de nitrogênio na forma de compostos gasosos, que ocorre em diversas situações, o que pode levar a uma baixa eficiência dos fertilizantes nitrogenados, principalmente em meio alcalino e quando aplicados em superfície (Alcarde et al. 1998, Lopes \& Guilherme 2000, Sousa \& Lobato 2004).

A forma de aplicação da ureia pode influenciar no aproveitamento do $\mathrm{N}$ pelo milho, onde sua aplicação a lanço sobre a superfície do solo pode ocasionar grandes perdas de $\mathrm{N}$ por volatilização de $\mathrm{NH}_{3}$ (Cantarella 2007). Segundo este autor, a presença de resíduos culturais sobre a superfície do solo aumenta as perdas de $\mathrm{NH}_{3}$, mais que em solos descobertos, devido à maior presença da uréase em palhada.

Em áreas sob Sistema Plantio Direto (SPD), a presença de restos culturais sobre a superfície do solo influencia na quantidade de $\mathrm{N}$ que se perde por volatilização, principalmente quando se utiliza a ureia (Cabezas 1998). Este autor relata as seguintes perdas acumuladas de $\mathrm{N}$-amoniacal da ureia, do uran (dissolução de ureia mais nitrato de amônio) e do sulfuran, quando estes fertilizantes foram aplicados em superfície, no cultivo em SPD: 78\%; 37,2\%; e $26,9 \%$ do $\mathrm{N}$ aplicado, respectivamente. Já com o uso de nitrato de amônio e sulfato de amônio, as perdas foram inferiores a $15 \%$ do $\mathrm{N}$ aplicado em superfície. $\mathrm{E}$ quando estas mesmas fontes foram incorporadas, a $5,0 \mathrm{~cm}$ de profundidade no solo, apresentaram perdas de $\mathrm{N}$ por volatilização inferiores a $5 \%$ do $\mathrm{N}$ aplicado, tanto para o SPD como para o plantio convencional. No plantio convencional, sem a incorporação das fontes, as perdas mais significativas foram de ureia $(30,7 \%)$ e uran $(9,7 \%)$.

Sangoi et al. (2003) observaram que a aplicação superficial de ureia, tanto em solo arenoso quanto em argiloso, aumenta as perdas de N por volatilização de amônia, em relação à sua incorporação, independentemente do manejo dos restos culturais de aveia preta, textura do solo, teor de matéria orgânica do solo (MOS) e da CTC do solo.
Para reduzir as perdas por volatilização de amônia, recomenda-se a incorporação dos fertilizantes nitrogenados amoniacais ou amídicos, em solos alcalinos ou calcários, associada à posterior e imediata irrigação. No caso da ureia, as perdas de $\mathrm{NH}_{3}$ podem chegar a quase $80 \%$, com a aplicação superficial no plantio direto, e $30 \%$, no plantio convencional, e a incorporação em, aproximadamente, 5,0-7,0 cm de profundidade no solo reduz, drasticamente, as perdas de amônia (Cabezas 1998).

Como o uso da ureia na agricultura está crescendo, estratégias para melhorar a sua eficiência, especialmente em áreas sob o sistema de plantio direto, estão sendo testadas. Dentre estas estratégias, incluem-se o uso de inibidores de uréase (NBPT) e de nitrificação, a adição de compostos acidificantes e adutos de ureia, a incorporação de ureia ao solo e o uso de ureia revestida com polímeros ou gel, também conhecidas como fertilizantes de libertação lenta ou controlada (Cantarella 2007).

Gans et al. (2006) estudaram a influência de dois inibidores de uréase na ureia, na cultura da aveia, verificando que os inibidores reduziram as perdas de $\mathrm{N}$ por volatilização de amônia e aumentaram o rendimento da aveia, quando comparado à ureia comum. Em outro estudo, em solo arenoso e argiloso, apesar da redução da volatilização de $\mathrm{N}$ pelo uso dos inibidores, estes não refletiram em maiores rendimentos, quando comparados à ureia na colheita de grãos da aveia (Gioacchini et al. 2002). Já Rozas et al. (1999), em área sob SPD, verificaram que o uso de ureia tratada com NBPT, que é um inibidor de uréase, não aumentou o rendimento do milho, nos três anos avaliados, quando comparado à ureia.

Tem-se buscado alternativas tecnológicas para que seja possível reduzir o custo e manter e/ou elevar a produtividade de grãos da cultura do milho. Uma destas tecnologias, disponível no mercado, refere-se ao uso de adubos nitrogenados revestidos com polímeros, que se enquadram no grupo dos fertilizantes de liberação lenta e no subgrupo dos produtos encapsulados ou recobertos (fertilizantes solúveis revestidos). Estes fertilizantes permitem reduzir as perdas de $\mathrm{N}$, que, normalmente, ocorrem com a utilização da ureia, fazendo com que haja uma barreira física das formas solúveis, contra a exposição do nutriente para o meio, evitando-se, assim, a atuação dos mecanismos de perdas.

Estudos evidenciaram que a produtividade das culturas pode ser mantida utilizando-se, aproxima- 
damente, $70-80 \%$ da dose de $\mathrm{N}$, em relação à dose dos produtos comumente utilizados (Blaylock 2007). Este mesmo autor observou aumento no rendimento de grãos e na recuperação aparente de $\mathrm{N}$ ( $\%$ do total de $\mathrm{N}$ aplicado como fertilizante), quando utilizada a ureia revestida com polímeros em cobertura no milho, que proporcionou rendimento de $12.240 \mathrm{~kg} \mathrm{ha}^{-1}$ e recuperação de $49 \%$, quando comparados com a ureia aplicada em cobertura, com $10.984 \mathrm{~kg} \mathrm{ha}^{-1} \mathrm{e}$ $35 \%$ de recuperação aparente de $\mathrm{N}$.

Nas condições edafoclimáticas dos Cerrados, estudos sobre o uso de polímeros, para a redução de perdas de $\mathrm{N}$, ainda são incipientes, o que justifica a avaliação do manejo no uso da ureia revestida com polímeros aplicada em superfície, comparada com a ureia incorporada ao solo, na cultura do milho. Com base no exposto, o presente trabalho teve como objetivos avaliar a eficiência agronômica e econômica do uso da ureia comum incorporada e da ureia revestida com polímeros em superfície, ambas aplicadas em cobertura na cultura do milho, em Neossolo Quartzarênico.

\section{MATERIAL E MÉTODOS}

O trabalho foi conduzido em cultivo de milho de verão, na safra 2007/2008, no município de Jataí, GO (51 $56^{\circ} 11$ "W, $18^{\circ} 01$ ' 11 'S e $801 \mathrm{~m}$ de altitude). O clima da região é classificado, segundo Köppen, como Awa, tropical de savana, mesotérmico, com chuva no verão e seca no inverno. O solo do local é caracterizado como Neossolo Quartzarênico órtico (RQo), de textura arenosa e relevo suavemente ondulado (IBGE 2007).

Foram coletadas amostras para caracterização granulométrica (Embrapa 1997) e de atributos químicos (Raij et al. 2001), na camada 0-0,2 m, com os seguintes resultados: $\mathrm{pH}\left(\mathrm{CaCl}_{2}\right)$ 5,10; 15,30 $\mathrm{g} \mathrm{dm}^{-3} \mathrm{MO} ; 10,65 \mathrm{mg} \mathrm{dm}^{-3} \mathrm{P}$ (Mehlich); $6,62 \mathrm{mg} \mathrm{dm}^{-3} \mathrm{~S} ; 19,6 \mathrm{mg} \mathrm{dm}{ }^{-3} \mathrm{~K} ; 2,08 \mathrm{cmol}_{\mathrm{c}} \mathrm{dm}^{-3}$ $\mathrm{Ca}+\mathrm{Mg} ; 1,68 \mathrm{cmol}_{c} \mathrm{dm}^{-3} \mathrm{Ca} ; 0,40 \mathrm{cmol}_{\mathrm{c}} \mathrm{dm}^{-3}$ $\mathrm{Mg} ; 0,03 \mathrm{cmol}_{\mathrm{c}} \mathrm{dm}^{-3} \mathrm{Al} ; 2,00 \mathrm{cmol}_{\mathrm{c}} \mathrm{dm}^{-3} \stackrel{\mathrm{c}}{\mathrm{H}}+\mathrm{Al}$; $2,13 \mathrm{cmol} \mathrm{dm}^{-3} \mathrm{SB} ; 4,13 \mathrm{cmol}_{\mathrm{c}} \mathrm{dm}^{-3}$ CTC; V $51,57 \% ; 0,21 \mathrm{mg} \mathrm{dm}^{-3} \mathrm{~B} ; 25,70 \mathrm{mg} \mathrm{dm}^{-3} \mathrm{Fe}$; $8,45 \mathrm{mg} \mathrm{dm}^{-3} \mathrm{Mn} ; 1,61 \mathrm{mg} \mathrm{dm}^{-3} \mathrm{Zn} ; 0,10 \mathrm{mg} \mathrm{dm}^{-3}$ Co; e $0,78 \mathrm{mg} \mathrm{dm}^{-3} \mathrm{Cu}$, bem como $87,72 \%, 5,64 \%$ e $6,64 \%$ de areia, argila e silte, respectivamente.

Aplicou-se, em superfície, $1,0 \mathrm{t} \mathrm{ha}^{-1}$ de calcário magnesiano (40,6\% de $\mathrm{CaO} ; 8,5 \%$ de $\mathrm{MgO}$; e PRNT de 84,34\%), dois meses antes da semeadura do milho de verão.
Após a colheita da soja e manejo da área com dessecante de ação total (glyphosate), foi semeada Brachiaria ruziziensis, como planta de cobertura e como cultura antecessora ao milho, ambas no sistema plantio direto. Para a implantação do experimento, foi realizada a dessecação da braquiária no estádio vegetativo (234 dias após a semeadura) com glyphosate (3,5 $\left.\mathrm{L} \mathrm{ha}^{-1}\right)$, juntamente com ácido bórico $\left(1,5 \mathrm{~kg} \mathrm{ha}^{-1}\right.$, com 17\% B), 13 dias antes da semeadura do milho.

Foi utilizado o milho híbrido P-30K73, com sementes apresentando $99 \%$ de germinação e previamente tratadas com tiametoxam $350 \mathrm{~g} \mathrm{~L}^{-1}$, na dose de $0,12 \mathrm{~L}$ do produto comercial, para 60.000 sementes. A semeadura do milho foi realizada no dia 20 de novembro de 2007, com o auxílio de semeadora para plantio direto, configurada para seis linhas, espaçadas em $86,0 \mathrm{~cm}$, e regulada para proporcionar população final de 60.000 plantas ha-1. A adubação de base foi de $32 \mathrm{~kg} \mathrm{ha}^{-1}$ de $\mathrm{N} ; 81 \mathrm{~kg} \mathrm{ha}^{-1}$ de $\mathrm{P}_{2} \mathrm{O}_{5} ; 73 \mathrm{~kg} \mathrm{ha}^{-1} \mathrm{de}$ $\mathrm{K}_{2} \mathrm{O}$; e $25 \mathrm{~kg} \mathrm{ha}^{-1}$ de enxofre (S); da fórmula comercial $08-20-18+6,2 \% \mathrm{~S}$. Este adubo foi depositado no sulco de semeadura, aproximadamente $8,0 \mathrm{~cm}$ abaixo da semente. Os resultados da análise de solo foram interpretados conforme indicação de Sousa \& Lobato (2004). A recomendação de adubação foi baseada na eficiência das fontes utilizadas e nos valores de extração e exportação destes nutrientes pela cultura (Fancelli \& Dourado Neto 2004).

O delineamento experimental foi em blocos casualizados, com oito repetições e três tratamentos, totalizando 24 parcelas. A unidade experimental foi composta por seis linhas de plantas, de 15,0 m de comprimento cada, onde a área útil constituiu-se de duas linhas centrais, de $10 \mathrm{~m}$ de comprimento cada, totalizando $17,2 \mathrm{~m}^{2}$.

Os tratamentos utilizados foram: Ureia $=$ ureia comum, incorporada ao solo $\left(232 \mathrm{~kg} \mathrm{ha}^{-1}\right.$, que equivale a $\left.104,40 \mathrm{~kg} \mathrm{ha}^{-1} \mathrm{de} \mathrm{N}\right)$; Ureia + Polímero = ureia revestida com polímeros, aplicada em superfície (234 $\mathrm{kg} \mathrm{ha}^{-1}$, que equivale a $96,41 \mathrm{~kg} \mathrm{ha}^{-1} \mathrm{de} \mathrm{N}$ ); e $1 / 2$ Ureia + Polímero $=$ ureia revestida com polímeros, aplicada em superfície (120 kg ha ${ }^{-1}$, que equivale a 49,44 $\mathrm{kg} \mathrm{ha}^{-1}$ de N). Esta discrepância na dose empregada se deve à variação do fluxo da ureia comum e da ureia revestida com polímeros, no equipamento de aplicação do produto a campo. O revestimento dos grânulos de ureia com polímeros foi efetuado pela própria empresa detentora da tecnologia. Para tal, utilizaram-se os seguintes produtos comerciais: KimCoat Poli N1 $\left(6,67 \mathrm{~L} \mathrm{t}^{-1}\right)$, KimCoat Poli N2 
$\left(61,1 \mathrm{~L} \mathrm{~kg} \mathrm{t}^{-1}\right)$ e KimCoat Poli N3 $\left(16,67 \mathrm{~kg} \mathrm{t}^{-1}\right)$, os quais foram adicionados, separadamente, sobre a ureia, em betoneira, para mistura e posterior ensaque.

A adubação nitrogenada de cobertura foi realizada em uma única aplicação, quando a cultura do milho apresentava-se no estádio $\mathrm{V}_{5}$, ou seja, plantas com cinco folhas totalmente expandidas (Fancelli \& Dourado Neto 2004). A ureia ( $45 \%$ de N) foi aplicada de forma incorporada, na entrelinha da cultura, com, aproximadamente, $7,0 \mathrm{~cm}$ de profundidade e a uma distância de $25,0 \mathrm{~cm}$ da linha de plantio do milho. Quanto à ureia revestida com polímeros (41,2\% de N), esta foi aplicada em superfície, sem incorporação, concentrada em faixa e depositada nas entrelinhas da cultura do milho, distantes, aproximadamente, 20,0-25,0 cm da linha de semeadura. Foi utilizado um cultivador com seis linhas, para a aplicação da ureia incorporada e da ureia revestida em superfície.

A adubação potássica em cobertura foi igual em todos os tratamentos, sendo aplicados $94,70 \mathrm{~kg} \mathrm{ha}^{-1}$ de cloreto de potássio $(\mathrm{KCl})$ em área total, por meio de um distribuidor de discos duplos rotativos.

Os tratos culturais (controle de pragas, doenças e ervas daninhas) utilizados na área experimental foram iguais em todos os tratamentos avaliados.

As características avaliadas em amostras de 10 plantas, coletadas ao acaso, antecedendo a colheita manual do milho e dentro da área útil da parcela experimental, foram: a) população de plantas, com a contagem de plantas produtivas (presença de espigas com grãos); b) altura de plantas da superfície do solo até a base da inflorescência masculina, em cm; c) altura de inserção de espiga, sendo a distância entre a superfície do solo e o ponto de inserção da espiga principal com o colmo, em cm; e d) diâmetro do colmo a $20,0 \mathrm{~cm}$ de altura do solo e em seu maior diâmetro, em cm. Em laboratório, foram feitas avaliações em todas as espigas coletadas de cada parcela, onde avaliaram-se os componentes rendimento de grãos; comprimento da espiga $(\mathrm{cm})$; diâmetro da espiga $(\mathrm{cm})$, mediante o uso de paquímetro, sendo o ponto considerado na avaliação o correspondente ao centro da espiga; número de fileiras por espiga, obtido pela contagem das fileiras; diâmetro do sabugo $(\mathrm{cm})$, determinado com o auxílio de paquímetro, no centro do sabugo; e massa de cem grãos (MCG, em g), corrigida para $13 \%$ de umidade, obtida de três subamostras coletadas ao acaso, contendo cem grãos cada (Soares 2003, Dourado Neto et al. 2004).
Avaliou-se, ainda, o número de grãos por espiga, calculado a partir da massa de grãos de milho de cada parcela, multiplicado por 100 e dividido pela MCG. Este resultado foi dividido pelo número de espigas por parcela. A prolificidade foi calculada pelo número total de espigas colhidas na área útil, dividido pelo número de plantas normais (com espigas e grãos). $\mathrm{O}$ rendimento foi determinado a partir da debulha e pesagem dos grãos oriundos de todas as espigas colhidas na área útil, corrigidas para $13 \%$ de umidade.

Utilizaram-se, para avaliação econômica, os indicadores gerados na área comercial da fazenda em que o ensaio foi conduzido e os preços agrícolas praticados na região de Jataí (GO), na safra 2007/2008. Os valores das operações agrícolas foram baseados em uma planilha formulada pela Fundação ABC (Castro - PR), referente ao mês de fevereiro de 2007 e adaptada às condições locais. Os custos variáveis (insumos, operações agrícolas e outros) por tratamento utilizado no experimento foram estimados a partir dos coeficientes técnicos registrados e usados no ensaio, extrapolados para 1,0 ha e ajustados às condições efetuadas e praticadas pela administração da fazenda, para o cultivo em área comercial de milho safra de verão, em Jataí. Portanto, os custos das operações agrícolas foram iguais para todos os tratamentos, principalmente em relação aos tratamentos com aplicação da ureia em cobertura (incorporada ou superficial e/ou revestida com polímeros), pois foi utilizado o mesmo equipamento para execução das aplicações da ureia, no experimento.

As produções obtidas em cada tratamento auxiliaram na obtenção da receita, utilizando-se o preço do milho-grão, referente ao mês de abril de 2008, em Jataí (GO), que foi de R\$21,00 por saca de $60 \mathrm{~kg}$. Para a receita bruta encontrada para cada tratamento, foi utilizada a média de rendimento obtida (em quilogramas por hectare) e esta multiplicada pelo preço de venda de cada quilograma de milho, que, no caso, foi de $\mathrm{R} \$ 0,35 \mathrm{~kg}^{-1}$.

A relação receita/custo, nos diferentes tratamentos, foi calculada em planilhas eletrônicas, por meio da divisão da receita bruta obtida com a venda do milho produzido por tratamento (média de rendimento) pelo total de custos variáveis calculados e estimados. A relação entre o valor recebido e o valor do investimento é, economicamente, viável, quando este índice for superior a 1,0 (Aguiar et al. 2008).

Foi efetuada a coleta e anotação do volume de precipitações ocorridas no período inerente à 
condução do experimento, por meio de pluviômetro tipo "cunha" (Figura 1).

Os dados climatológicos relativos ao período experimental são apresentados na Figura 2, tendo sido coletados em posto meteorológico automatizado, instalado na unidade Jatobá da UFG - Campus Jataí, Jataí, GO.

Os dados referentes às avaliações realizadas foram submetidos a análise de variância e teste $\mathrm{F}$ e, quando significativas, as médias foram comparadas pelo teste Tukey, a 5\%.

\section{RESULTADOS E DISCUSSÃO}

A população total de plantas produtivas não diferiu entre os tratamentos (Tabela 1). Isto deve-se, em parte, à homogeneidade na distribuição e à uniformidade na emergência das plantas de milho. Sabe-se que o manejo da densidade de plantas é uma das práticas culturais mais importantes, pois irá determinar o rendimento de grãos no milho. $\mathrm{O}$ estande afeta a arquitetura das plantas, altera o crescimento e o desenvolvimento e influencia no rendimento

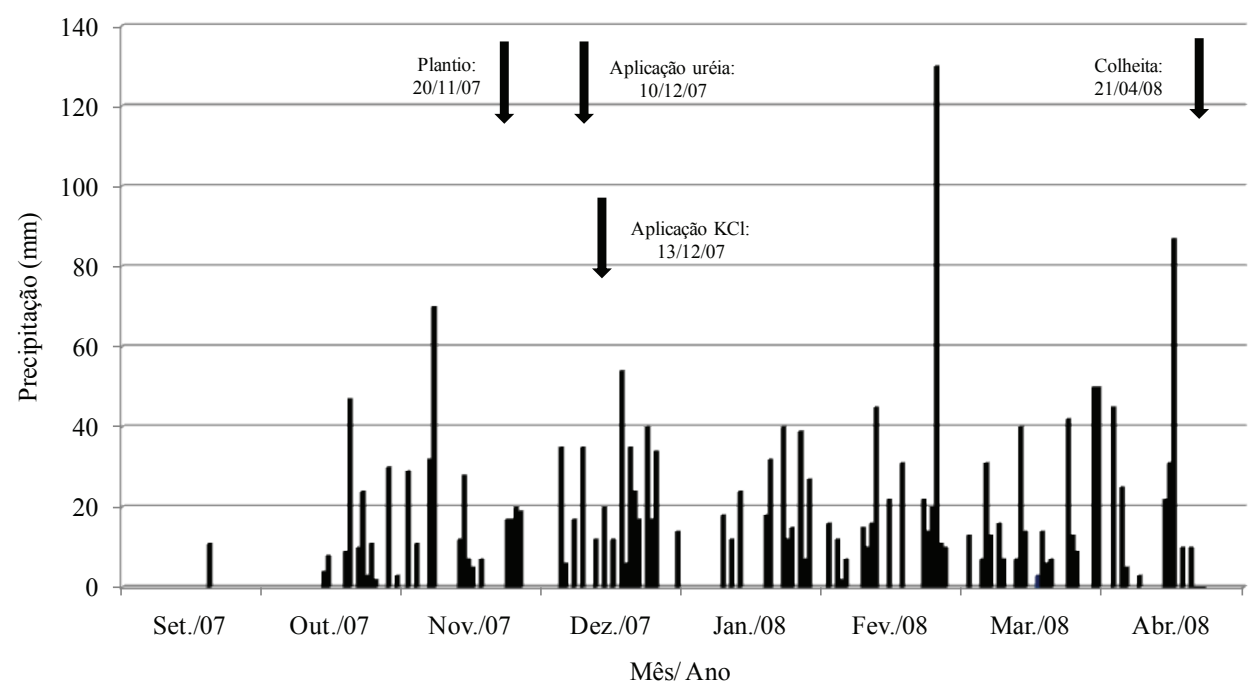

Figura 1. Precipitação ocorrida e práticas agrícolas realizadas na cultura do milho, de 01/09/2007 a 30/04/2008 (Jataí, GO).

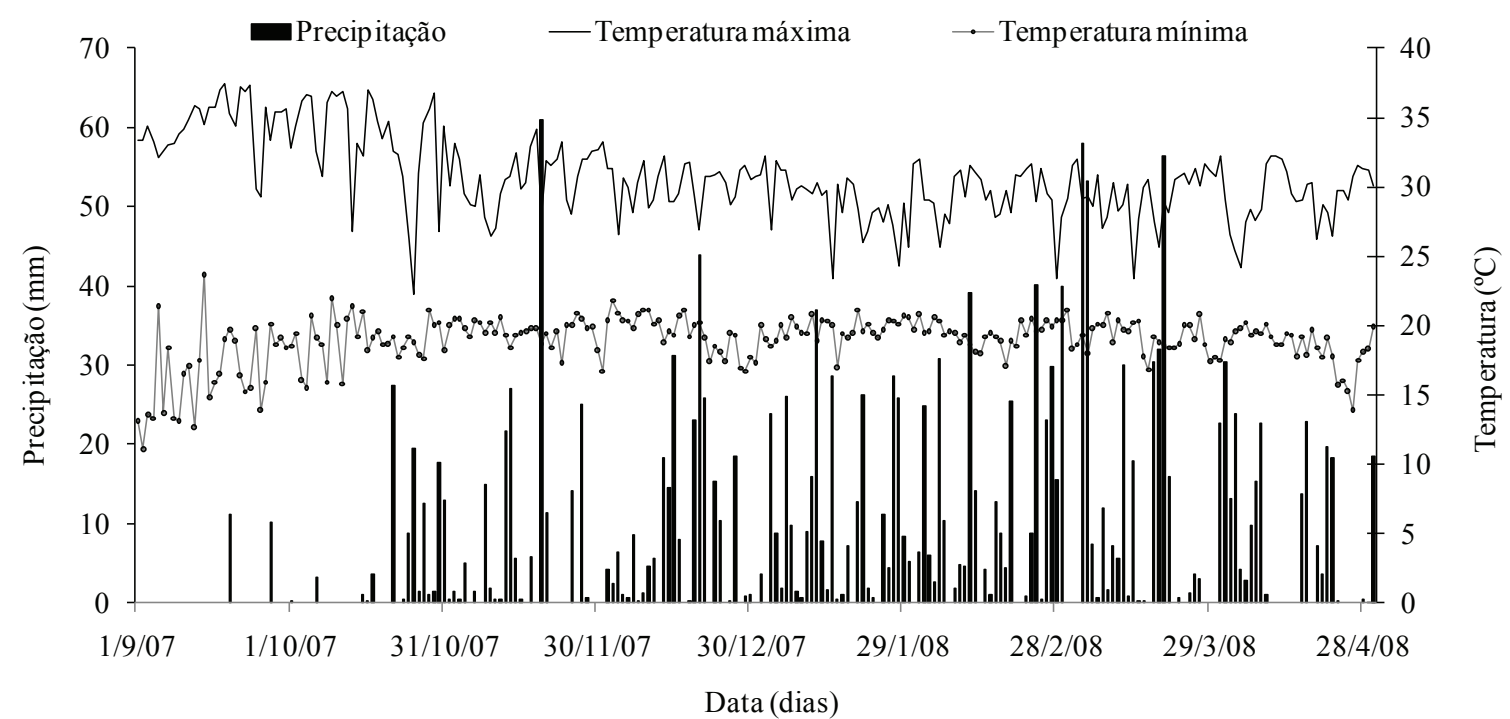

Figura 2. Precipitação pluviométrica, temperatura máxima e mínima, ocorridas de 01/09/2007 a 30/04/2008, coletadas na Estação Climatológica da UFG - Campus Jataí (Jataí, GO). 
Tabela 1. População total de plantas produtivas (PopPl), altura de plantas (AltPl), altura de espigas (AltEsp), diâmetro do colmo (DCol), comprimento de espiga (CEsp), diâmetro de espiga (DEsp), número de grãos por espiga (NGEsp) e massa de cem grãos (MCG) do milho, em função dos tratamentos com o uso da ureia incorporada e ureia revestida aplicada em superfície (Jataí, GO, safra 2007/2008).

\begin{tabular}{ccccccccc}
\hline \multirow{2}{*}{ Tratamento } & PopPl & \multirow{2}{*}{ AltPl } & AltEsp & \multirow{2}{*}{ DCol } & CEsp & DEsp & NGEsp & \multirow{2}{*}{ MCG } \\
\cline { 2 - 8 } & \multicolumn{1}{c}{$\left(\mathrm{pl} \mathrm{ha}^{-1}\right)$} & $(\mathrm{cm})$ & $(\mathrm{cm})$ & $(\mathrm{cm})$ & $(\mathrm{cm})$ & $(\mathrm{cm})$ & \multicolumn{1}{c}{$\left(\mathrm{n}^{\circ}\right)$} & $(\mathrm{g})$ \\
\hline 1/2 Ureia + Polímero & 51.962 & 202,39 & 103,24 & 2,17 & $12,24 \mathrm{c}$ & $4,34 \mathrm{~b}$ & $391,18 \mathrm{~b}$ & $29,67 \mathrm{~b}$ \\
Ureia + Polímero & 55.596 & 208,82 & 109,37 & 2,26 & $12,94 \mathrm{~b}$ & $4,38 \mathrm{~b}$ & $420,13 \mathrm{a}$ & $29,64 \mathrm{~b}$ \\
Ureia & 53.852 & 210,67 & 111,07 & 2,22 & $13,81 \mathrm{a}$ & $4,50 \mathrm{a}$ & $432,57 \mathrm{a}$ & $31,77 \mathrm{a}$ \\
\hline CV $(\%)$ & 8,65 & 3,33 & 5,80 & 3,13 & 2,52 & 1,00 & 3,03 & 3,35 \\
\hline Média & 53.803 & 207,30 & 107,89 & 2,22 & 12,99 & 4,41 & 414,63 & 30,36 \\
\hline
\end{tabular}

Médias seguidas da mesma letra, na coluna, não diferem, estatisticamente, entre si, pelo teste Tukey, a $5 \%$.

de grãos e partição de fotoassimilados (Almeida \& Sangoi 1996, Merotto Júnior et al. 1999).

A forma e as doses aplicadas da ureia convencional (comum) e da ureia revestida com polímeros não influenciaram os componentes altura de planta, altura de inserção da primeira espiga, diâmetro do colmo (Tabela 1), prolificidade de espigas, diâmetro médio do sabugo e número de fileiras por espigas (Tabela 2).

Quanto ao comprimento médio de espigas de milho, a ureia incorporada proporcionou maior valor médio $(13,81 \mathrm{~cm})$, seguido da maior dose de ureia polimerizada aplicada em superfície $(12,94 \mathrm{~cm})$ e, por último, do tratamento com metade da dose de ureia polimerizada $(12,24 \mathrm{~cm})$, evidenciando que as maiores doses aplicadas e, principalmente a forma de aplicação da ureia, influenciaram, diretamente, no comprimento de espiga (Tabela 1).

Com relação ao diâmetro médio da espiga, o tratamento com a ureia incorporada foi superior a ambos os tratamentos com ureia revestida com polí- meros aplicados em superfície, os quais não diferiram entre si (Tabela 1).

Quanto ao número de grãos por espiga, a ureia revestida (120 $\left.\mathrm{kg} \mathrm{ha}^{-1}\right)$ aplicada em superfície foi inferior aos tratamentos com ureia incorporada (232 $\left.\mathrm{kg} \mathrm{ha}^{-1}\right)$ e ureia revestida com polímeros (234 $\left.\mathrm{kg} \mathrm{ha}^{-1}\right)$ aplicada em superfície, os quais não diferiram entre si, indicando que, para este componente, não houve diferença entre as fontes de nitrogênio, quando se aplicou a mesma dose (Tabela 1).

Quanto à massa de 100 grãos, a ureia incorporada foi superior a ambos os tratamentos com ureia revestida, aplicados em superfície, os quais não diferiram entre si, o que evidencia que a ureia incorporada foi mais propícia ao enchimento de grãos e aumento da sua densidade, em comparação com a ureia revestida aplicada em superfície (Tabela 1).

O diâmetro, o comprimento e o número de espigas, além da densidade dos grãos, são características que determinam o potencial produtivo do

Tabela 2. Prolificidade de espiga (Prolif), diâmetro do sabugo (DSab), número de fileiras por espiga (NFilEsp), rendimento de grãos (Rend), análise econômica da receita bruta (RecBrt), estimativa de custo de produção (EstCust), lucro obtido por hectare (Lucro) e relação entre o valor recebido e o valor do investimento (Rec/Invest), em função dos tratamentos com ureia incorporada e ureia revestida aplicada em superfície (Jataí, GO, safra 2007/2008).

\begin{tabular}{|c|c|c|c|c|c|c|c|c|}
\hline \multirow{2}{*}{ Tratamento } & Prolif & DSab & NFilEsp & Rend & RecBrt & EstCusto & Lucro & Rec/Invest \\
\hline & & $(\mathrm{cm})$ & $\left(\mathrm{n}^{\mathrm{o}}\right)$ & $\left(\mathrm{kg} \mathrm{ha}^{-1}\right)$ & $\left(\mathrm{R} \$ \mathrm{ha}^{-1}\right)$ & $\left(\mathrm{R} \$ \mathrm{ha}^{-1}\right)$ & $\left(\mathrm{R} \$ \mathrm{ha}^{-1}\right)$ & \\
\hline $1 / 2$ Ureia + Polímero & 1,09 & 2,23 & 13,12 & $6.567 \mathrm{c}$ & $2.298,47 \mathrm{c}$ & $2.024,14 \mathrm{c}$ & $274,32 b$ & $1,13 \mathrm{~b}$ \\
\hline Ureia + Polímero & 1,08 & 2,23 & 13,10 & $7.429 \mathrm{~b}$ & $2.600,22 \mathrm{~b}$ & $2.186,72 \mathrm{a}$ & $413,50 \mathrm{~b}$ & $1,19 \mathrm{~b}$ \\
\hline Ureia & 1,12 & 2,30 & 13,07 & $8.278 \mathrm{a}$ & $2.897,23 \mathrm{a}$ & $2.117,79 \mathrm{~b}$ & $779,44 \mathrm{a}$ & $1,37 \mathrm{a}$ \\
\hline CV (\%) & 4,00 & 2,27 & 1,14 & 6,74 & 6,74 & 0,41 & 34,03 & 6,39 \\
\hline Média & 1,10 & 2,25 & 13,10 & 7.425 & $2.598,64$ & $2.109,55$ & 489,09 & 1,23 \\
\hline
\end{tabular}

Médias seguidas da mesma letra, na coluna, não diferem, estatisticamente, entre si, pelo teste Tukey, a $5 \%$. 
milho. O diâmetro de espiga está frequentemente relacionado ao enchimento de grãos e ao número de fileiras de grãos por espiga (Ohland et al. 2005).

A forma de aplicação, a dose e a fonte da ureia utilizada em cobertura no milho tiveram efeito significativo sobre o rendimento de grãos. A maior produtividade de grãos foi obtida com a ureia incorporada, seguida da maior dose de ureia polimerizada em superfície. A menor produtividade de grãos foi obtida quando se usou a menor dose de nitrogênio, com a ureia revestida aplicada em superfície (Tabela 2). Aita et al. (2001) encontraram acréscimo na produtividade do milho, com o aumento das doses de $\mathrm{N}$ na cultura do milho, em área sob plantio direto, demonstrando que a quantidade de $\mathrm{N}$ exerce influencia na produtividade do milho.

A ureia incorporada ao solo propiciou o maior comprimento médio de espigas $(13,81 \mathrm{~cm})$, o maior diâmetro médio da espiga $(4,50 \mathrm{~cm})$, o maior número de grãos por espiga (432,57 grãos), a maior massa de cem grãos (31,77 g) (Tabela 1) e, em consequência, a maior produtividade de grãos de milho $\left(8.278 \mathrm{~kg} \mathrm{ha}^{-1}\right)$ (Tabela 2). Assim, constatou-se incremento de $20,67 \%$ no rendimento de grãos $\left(1.711 \mathrm{~kg} \mathrm{ha}^{-1}\right)$ observado na ureia incorporada $\left(232 \mathrm{~kg} \mathrm{ha}^{-1}\right)$, em relação à ureia revestida $\left(120 \mathrm{~kg} \mathrm{ha}^{-1}\right)$ aplicada em superfície, e incremento de $10,26 \%$ no rendimento de grãos (849 $\mathrm{kg} \mathrm{ha}^{-1}$ ) observado quando ocorreu aplicação da ureia incorporada $\left(232 \mathrm{~kg} \mathrm{ha}^{-1}\right)$, em relação à maior dose de ureia revestida aplicada em superfície.

Estudo realizado em Goiás, em área sob SPD, comprovou que a época e o modo de aplicação do $\mathrm{N}$ influenciam na produtividade de grãos de milho, sendo os melhores resultados obtidos com a incorporação do fertilizante na semeadura ou aos 15 dias após a emergência das plântulas, obtendo-se $670 \mathrm{~kg} \mathrm{ha}^{-1}$ a mais, com a incorporação do fertilizante, em relação à aplicação em superfície (Silva et al. 2005). Pöttker \& Wiethölter (2004) também verificaram, na média de cinco anos de avaliação, que a incorporação do $\mathrm{N}$ ao solo aumentou o rendimento do milho em cerca de 5\%, em relação à sua aplicação em cobertura sem incorporação, para as condições do Rio Grande do Sul.

A ureia incorporada ao solo propiciou a maior receita bruta por hectare ( $\mathrm{R} \$ 2.897,23)$. A menor receita foi verificada quando se aplicou $120 \mathrm{~kg} \mathrm{ha}^{-1}$ de ureia revestida em superfície ( $\mathrm{R} \$ 2.298,47$ por hectare). Já o uso da ureia + polímeros em superfície
(234 $\left.\mathrm{kg} \mathrm{ha}^{-1}\right)$ propiciou receita bruta por hectare intermediária $(\mathrm{R} \$ 2.600,22)$ e, também, o maior custo de produção por hectare $(\mathrm{R} \$ 2.186,72)$. A aplicação de $120 \mathrm{~kg} \mathrm{ha}^{-1}$ da ureia com o revestimento teve o menor custo de produção por hectare (R \$ 2.024,14), com diferença de $\mathrm{R} \$ 162,58$ (Tabela 2).

Quanto ao lucro obtido em Reais por hectare, a ureia incorporada foi superior a ambos os tratamentos com ureia revestida aplicada em superfície, os quais não diferiram entre si. A ureia incorporada $\left(232 \mathrm{~kg} \mathrm{ha}^{-1}\right)$ propiciou incremento de $1.046 \mathrm{~kg} \mathrm{ha}^{-1} \mathrm{ou}$ $365,94 \mathrm{R} \$$ ha $^{-1}$ no lucro, em comparação com a ureia revestida com polímeros $\left(234 \mathrm{~kg} \mathrm{ha}^{-1}\right)$ aplicada em superfície. Apesar de não diferirem estatisticamente, a ureia revestida com polímeros $\left(234 \mathrm{~kg} \mathrm{ha}^{-1}\right)$ propiciou incremento de $398 \mathrm{~kg} \mathrm{ha}^{-1}$ ou 139,18 $\mathrm{R} \$ \mathrm{ha}^{-1}$ no lucro, em comparação com a ureia com o revestimento de polímeros (120 kg ha-1), ambas aplicadas em superfície. Tais resultados contribuíram para que a ureia incorporada ao solo propiciasse o maior lucro $\left(2.227 \mathrm{~kg} \mathrm{ha}^{-1} \mathrm{ou}\right.$

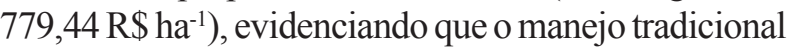
da ureia incorporada ao solo proporcionou lucratividade superior aos tratamentos com ureia revestida com polímeros em superfície (Tabela 2).

Quanto ao (Rec/Invest), ou seja, à relação entre o valor recebido e o valor do investimento, a ureia incorporada foi superior a ambos os tratamentos com ureia revestida aplicada em superfície, os quais não diferiram entre si. A ureia incorporada ao solo propiciou o maior índice de Rec/Invest $(1,37)$, ou seja, para cada Real $(\mathrm{R} \$ 1,00)$ investido, retornou-se um Real e trinta e sete centavos ( $\$$ \$ 1,37). A ureia revestida com polímeros $\left(234 \mathrm{~kg} \mathrm{ha}^{-1}\right)$ aplicada em superfície obteve índice de Rec/Invest intermediário $(1,19)$ e o tratamento com a aplicação de $120 \mathrm{~kg} \mathrm{ha}^{-1}$ da ureia com o revestimento de polímeros aplicada em superfície obteve o menor índice de Rec/Invest $(1,13)$, indicando que o manejo tradicional da ureia incorporada ao solo proporcionou viabilidade econômica superior aos tratamentos com ureia revestida com polímeros em superfície (Tabela 2).

\section{CONCLUSÕES}

1. A ureia comum incorporada ao solo propicia maior rendimento de grãos de milho e maior lucratividade do que a ureia revestida aplicada em superfície.

2. A redução da dose de ureia revestida com polímeros promove redução no rendimento de grãos do milho. 


\section{REFERÊNCIAS}

AGUIAR, R. A. de et al. Análise econômica de diferentes práticas culturais na cultura do milho (Zea mays L.). Pesquisa Agropecuária Tropical, Goiânia, v. 38, n. 4, p. 241-248, 2008.

AITA, C. et al. Plantas de cobertura de solo como fonte de nitrogênio ao milho. Revista Brasileira de Ciência do Solo, Viçosa, v. 25, n. 1, p. 157-165, 2001.

ALCARDE, J. C.; GUIDOLIN, J. A.; LOPES, A. S. Os adubos e a eficiência das adubações. 3. ed. São Paulo: Associação Nacional para Difusão de Adubos e Corretivos, 1998.

ALMEIDA, M. L. de; SANGOI, L. Aumento da densidade de plantas de milho para regiões de curta estação estival de crescimento. Pesquisa Agropecuária Gaúcha, Porto Alegre, v. 2, n. 2, p. 179-183, 1996.

BLAYLOCK, A. O futuro dos fertilizantes nitrogenados de liberação controlada. Informações Agronômicas, Piracicaba, n. 120, p. 8-10, dez. 2007.

CABEZAS, W. A. R. L. Comportamento dos adubos nitrogenados em clima e solo de Cerrado. In: CURSO SOBRE ASPECTOS BÁSICOS DE FERTILIDADE E MICROBIOLOGIA DO SOLO SOB PLANTIO DIRETO, 1., 1998, Rio verde. Resumos... Rio Verde: Aldeia Norte, 1998. p. 78-92.

CANTARELLA, H. Nitrogênio. In: NOVAIS, R. F. et al. (Eds.). Fertilidade do solo. Viçosa: SBCS, 2007. p. 375470 .

DOURADO NETO, D. et al. Aplicação e influência do fitoregulador no crescimento das plantas de milho. Revista da Faculdade de Zootecnia, Veterinária e Agronomia, Uruguaiana, v. 11, n. 1, p. 93-102, 2004.

EMPRESA BRASILEIRA DE PESQUISA AGROPECUÁRIA (Embrapa). Manual de métodos de análises de solo. 2. ed. Rio de Janeiro: Ministério da Agricultura e do Abastecimento, 1997.

FANCELLI, A. L.; DOURADO NETO, D. Produção de milho. 2. ed. Guaíba: Agropecuária, 2004.

GANS, W.; HERBST, F.; MERBACH, W. Nitrogen balance in the system plant-soil after urea fertilization combined with urease inhibitors. Plant Soil Environment, Prague, v. 52, special issue, p. 36-38, 2006.

GIOACCHINI, P. et al. Influence of urease and nitrification inhibitors on $\mathrm{N}$ losses from soils fertilized with urea. Biology and Fertility of Soils, New York, v. 36, n. 2, p. 129-135, 2002.

INSTITUTO BRASILEIRO DE GEOGRAFIA E ESTATÍSTICA (IBGE). Manual técnico de pedologia. 2. ed. Rio de Janeiro: IBGE, 2007.
INTERNATIONAL FERTILIZER INDUSTRY ASSOCIATION (IFA). Ifadata. 2009. Disponível em: $<$ http://www.fertilizer.org/ifa/ifadata/results $>$. Acesso em: 29 jun. 2009.

LOPES, A. S.; GUILHERME, L. R. G. Uso eficiente de fertilizantes e corretivos agrícolas: aspectos agronômicos. 3. ed. São Paulo: Associação Nacional para Difusão de Adubos e Corretivos, 2000.

MEROTTO JÚNIOR, A. et al. A desuniformidade de emergência reduz o rendimento de grãos de milho. Ciência Rural, Santa Maria, v. 29, n. 4, p. 591-601, 1999.

OHLAND, R. A. A. et al. Culturas de cobertura do solo e adubação nitrogenada no milho em plantio direto. Ciência e Agrotecnologia, Lavras, v. 29, n. 3, p. 538-544, 2005.

OLIVEIRA, E. F. de; BALBINO, L. C. Efeitos de fontes e doses de nitrogênio aplicado em cobertura nas culturas de trigo, milho e algodão. In: OLIVEIRA, E. F. de; BALBINO, L. C. Resultados de pesquisa, 1/95. Cascavel: Ocepar, 1995.

PÖTTKER, D.; WIETHÖLTER, S. Épocas e métodos de aplicação de nitrogênio em milho cultivado no sistema plantio direto. Ciência Rural, Santa Maria, v. 34, n. 4, p. 1015-1020, 2004.

RAIJ, B. van et al. Análise química para avaliação da fertilidade de solos tropicais. Campinas: Instituto Agronômico, 2001.

ROZAS, H. S. et al. No-till maize nitrogen uptake and yield: effect of urease inhibitor and application time. Agronomy Journal, Madison, v. 91, n. 6, p. 950-955, 1999.

SANGOI, L. et al. Volatilização de N-NH $\mathrm{NH}_{3}$ em decorrência da forma de aplicação de ureia, manejo de resíduos e tipo de solo, em laboratório. Ciência Rural, Santa Maria, v. 33, n. 4, p. 687-692, 2003.

SILVA, E. C. da et al. Épocas e formas de aplicação de nitrogênio no milho sob plantio direto em solo de Cerrado. Revista Brasileira de Ciência do Solo, Viçosa, v. 29, n. 5, p. 725-733, 2005.

SOARES, M. A. Influência de nitrogênio, zinco e boro e de suas respectivas interações no desempenho da cultura do milho (Zea mays L.). 2003. 92 f. Dissertação (Mestrado em Agronomia)-Escola Superior de Agricultura "Luiz de Queiroz”, Universidade de São Paulo, Piracicaba, 2003.

SOUSA, D. M. G. de; LOBATO, E. Adubação com nitrogênio. In: SOUSA, D. M. G. de; LOBATO, E. Cerrado: correção do solo e adubação. 2. ed. Brasília, DF: Embrapa Informação Tecnológica, 2004. p. 129-145. 